\title{
Gaming disorder: what doctors need to know
}

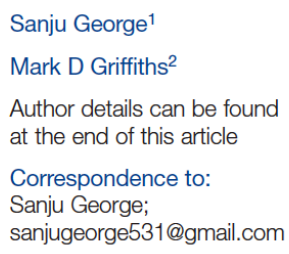

Sanju George ${ }^{1}$

Mark D Griffiths ${ }^{2}$

Author details can be found at the end of this article

Correspondence to:

Sanju George;

sanjugeorge531@gmail.com

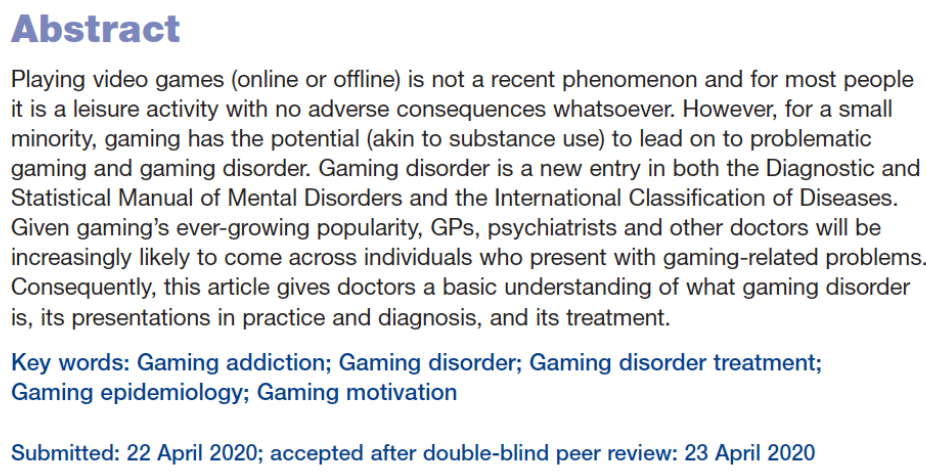

Playing video games (online or offline) is not a recent phenomenon and for most people it is a leisure activity with no adverse consequences whatsoever. However, for a small minority, gaming has the potential (akin to substance use) to lead on to problematic gaming and gaming disorder. Gaming disorder is a new entry in both the Diagnostic and Statistical Manual of Mental Disorders and the International Classification of Diseases. Given gaming's ever-growing popularity, GPs, psychiatrists and other doctors will be increasingly likely to come across individuals who present with gaming-related problems.

Consequently, this article gives doctors a basic understanding of what gaming disorder is, its presentations in practice and diagnosis, and its treatment.

Key words: Gaming addiction; Gaming disorder; Gaming disorder treatment; Gaming epidemiology; Gaming motivation

Submitted: 22 April 2020; accepted after double-blind peer review: 23 April 2020

\begin{abstract}
Playing video games (online or offline) is not a recent phenomenon and for most it is a leisure activity with no adverse consequences whatsoever. However, for a small minority, gaming has the potential (akin to substance use) to lead on to problematic gaming and gaming disorder (GD). Gaming disorder is a new entrant in both the DSM-5 and ICD-11. Given gaming's ever-growing popularity, GPs, psychiatrists and other doctors will be increasingly likely to come across individuals who present with gaming-related problems. Consequently, the present paper equips doctors with a basic understanding of what GD is, its presentations in practice and diagnosis, and its treatment.
\end{abstract}

Keywords: Gaming disorder; Gaming addiction; Gaming epidemiology; Gaming motivation; Gaming disorder treatment. 


\section{Key points}

- GD is a pattern of gaming behaviour ("digital-gaming" or "video-gaming") characterized by impaired control over gaming, increasing priority given to gaming over other activities to the extent that gaming takes precedence over other interests and daily activities, and continuation or escalation of gaming despite the occurrence of negative consequences.

- Given gaming's ever-growing popularity, doctors will be increasingly likely to come across individuals who present with gaming-related problems. Consequently, doctors (GPs, hospital doctors and psychiatrists) need to be equipped with at least a basic understanding of what GD is, its presentations in practice and diagnosis, and its treatment.

- There are several, easy-to-use screening tools available for use.

- There is no universally accepted or unequivocally evidenced treatment for GD; no pharmacological agent has yet been licensed for use in this condition; and At present, psychological treatments remain the mainstay, of which cognitive-behaviour therapy is the most popular. 


\section{Introduction}

Gaming disorder is a relatively new entrant in the psychiatric lexicon, although the construct has existed in different guises for over 35 years (Griffith, Kuss \& King, 2012). Considerable nosological ambiguity surrounds this disorder, with DSM-5 preferring the term 'Internet Gaming Disorder' (IGD) (APA, 2013) and ICD-11 terming it 'Gaming disorder' (GD) (WHO, 2018). Furthermore, experts are not yet close to consensus on its precise definition, screening and measurement tools, and treatment strategies. The International Classification of Diseases (ICD-11, 11th Revision) defines GD 'as a pattern of gaming behaviour ("digitalgaming" or "video-gaming") characterized by impaired control over gaming, increasing priority given to gaming over other activities to the extent that gaming takes precedence over other interests and daily activities, and continuation or escalation of gaming despite the occurrence of negative consequences' (WHO, 2018 - see Box 1).

Playing video games (online or offline) is not a recent phenomenon and for most it is a leisure activity with no adverse consequences whatsoever and can have both therapeutic benefits (Griffiths, 2019) and cognitive benefits (Nuyens, Kuss, Lopez-Fernandez, Griffiths, 2019). However, for a small minority, gaming has the potential (akin to substance use) to lead on to problematic gaming and GD (Naskar, Victor, Nath, Sengupta, 2016). Online gaming is a rapidly expanding multi-billion dollar industry (Batchelor, 2017). Given gaming's evergrowing popularity, doctors will be increasingly likely to come across individuals who present with gaming-related problems. Consequently, doctors (GPs, hospital doctors and psychiatrists) need to be equipped with at least a basic understanding of what GD is, its presentations in practice and diagnosis, and its treatment. 


\section{Epidemiology and gaming motivation}

Videogames have evolved considerably in their characteristics, complexity, and interactive potential over the past few decades from offline single-player games in the 1970s (e.g., Space Invaders) to online games where players can interact with each other within the game itself (Massively Multiplayer Online Role-Playing Games such as World of Warcraft). More recently, online video games such as Fortnite, a Multiplayer Online Battle Arena (MOBA) game, have attracted millions of individuals playing concurrently online (Chalk, 2018). Over the past few years, accessibility to online games has greatly increased via the playing on different types of hardware including computer gaming (via laptop or home personal computer), console gaming (via dedicated gaming equipment such as PlayStation and Xbox consoles), and mobile gaming (via Android or Apple apps on smart phones and tablets) (Columb, Griffiths \& O’Gara, 2019).

Although methodological differences among studies preclude precise estimates of the prevalence rates of GD, researchers agree that it is a global phenomenon. Most studies in this field have emerged from Asia, Americas, Australia, and Europe. King and Delfabbro (2018) reported prevalence rates of GD to range from 0.3 to $3.1 \%$ among adults with slightly higher prevalence rates among adolescents (Gentile et al, 2017). It has consistently been found that GD is more common in males than females (Fam, 2018) with adolescents and emerging adults being the most vulnerable (King \& Delfabbro, 2018; Sampogna et al, 2018).

Empirically, the main motives for gaming have been shown to be for recreation (playful and relaxing aspects), competition (beating opponents and achievement aspects), sociability (for social and friendship aspects), skill development (improving cognitive aspects), fantasy (experiencing aspects not possible in real life), coping (mood improving and aggression 
channelling aspects), and escape (avoiding reality and problems) (Ballabio et al, 2017). Unsurprisingly, playing videogames to avoid everyday problems (i.e., escape) appears to be the motivation most associated with psychiatric distress and in predicting disordered gaming (Ballabio et al, 2017).

At present, it appears that few disordered gamers present to psychiatrists. There may be a number of reasons for this including the fact that addicted adolescents do not seek treatment more generally (Griffiths, 2015) and the fact that gaming is viewed as a meaningful and purposeful activity, and as a large part of gamers' lives (Shi et al, 2019). However, the minority of gamers who develop GD either present to psychiatrists for help to cut down or stop gaming, or for help in treating its comorbidities. In a systematic review, González-Bueso et al (2018) reported that GD is most commonly associated with a number of psychiatric disorders including anxiety (92\%), depression (89\%), Attention Deficit Hyperactivity Disorder (ADHD)/ hyperactivity (89\%), and social phobia/obsessive compulsive symptoms (75\%). Related to this, recent research from GD treatment-seeking adolescents in Spain demonstrated various different aetiological pathways into problematic gaming (TorresRodríguez et al, 2018a,b,c; Torres-Rodríguez et al, 2019) highlighting that disordered gaming can occur without any other major comorbidities as well as co-occurring with ADHD, bipolar disorder, and autism.

Recent research has also begun to examine GD's relationship with other potentially addictive behaviours. A recent systematic review by Burleigh et al (2019) reported 20 studies had examined the co-occurrence of GD with other addictive behaviours and reported that disordered gaming can co-occur with behaviours such as alcohol use disorder and addictive use of social media. For instance a large scale survey by Van Rooij et al (2014) reported 
nicotine, alcohol, and cannabis use to be twice as common among male adolescent disordered gamers as compared to their non-problematic gaming peers. More research is needed to determine whether GD is the cause or consequence of these various comorbidities.

\section{Screening and diagnosis}

There is no consensus on the best screening tool for GD. A systematic review by King et al (2013) noted there had been 18 different screening instruments used in 63 quantitative studies $(\mathrm{N}=58,415)$ although all these studies were prior to the publication of the DSM-5 criteria for IGD. Since that review, a number of psychometric screening instruments have been developed utilizing the nine DSM criteria (see Box 2) including the Internet Gaming Disorder Scale (Lemmens, Valkenburg \& Gentile, 2015) (IGDS) and the nine-item Internet Gaming Disorder Scale-Short Form (Pontes \& Griffiths, 2015) (IGDS9-SF). Currently, the most used scale is the IGDS-SF9 which has been used in many studies of English-speaking populations (e.g., UK, USA, Australia), non-English-speaking populations but carried out using the English version of the IGD9-SF (e.g., India, Hong Kong, Lebanon) as well as being validated in Chinese, Persian, Italian, Portuguese, Slovenian and Albanian (Arıcak et al, 2019; de Palo et al, 2019; Evren et al, 2018; Hawi et al, 2018; Leung et al, 2019; Pontes \& Griffiths, 2016; Pontes, Macur \& Griffiths, 2016; .Wu et al, 2018). The scale has been shown to have very good reliability and validity in all studies.

\section{Box 1. ICD-11 diagnostic criteria for Gaming Disorder (WHO, 2018)}

- A pattern of gaming behaviour (“digital-gaming" or "video-gaming") characterized by impaired control over gaming, increasing priority given to gaming over other activities to the extent that gaming takes precedence over other interests and daily 


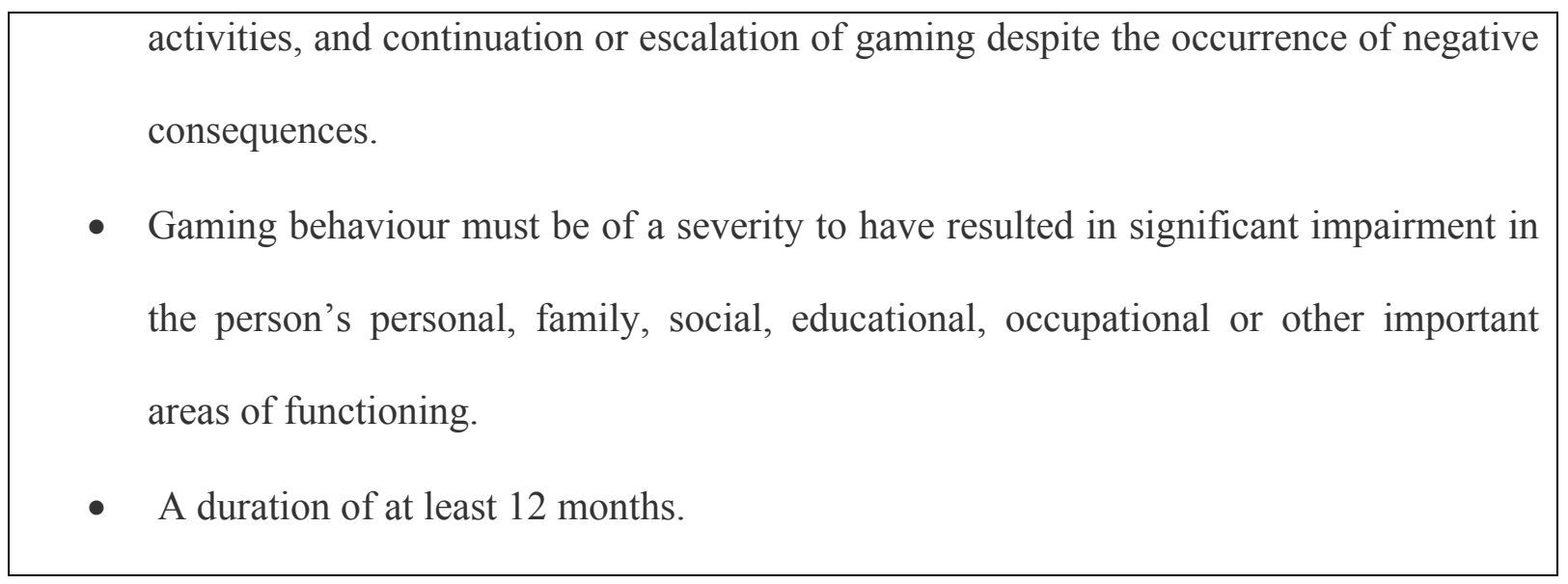

\section{Box 2. DSM-5diagnostic criteria for Internet Gaming Disorder (APA, 2013)}

For a diagnosis of IGD, the person must have met five or more of the following criteria in a 12-month period:

(1) preoccupation with Internet gaming;

(2) withdrawal symptoms when Internet is taken away

(3) tolerance: the need to spend increasing amounts of time engaged in Internet gaming

(4) unsuccessful attempts to control Internet gaming use

(5) continued excessive Internet use despite knowledge of negative psychosocial problems (6) loss of interests, previous hobbies, entertainment as a result of, and with the exception of Internet gaming use

(7) use of the Internet gaming to escape or relieve a dysphoric mood

(8) has deceived family members, therapists, or others regarding the amount of Internet gaming

(9) has jeopardized or lost a significant relationship, job, or educational or career opportunity because of Internet gaming use 


\section{Treatment}

There is no universally accepted or unequivocally evidenced treatment for GD (King et al, 2011; King et al, 2017). No pharmacological agent has yet been licensed for use in this condition. At present, psychological treatments remain the mainstay. Cognitive-behaviour therapy (CBT) is the most popular treatment modality that has been tried, with some success in the short-term both in improving symptoms of GD and in alleviating symptoms of coexisting depression (Stevens et al, 2018). More research is warranted to examine the relative merits of one-to-one therapy, group therapies, face-to-face vs. online psychological interventions, etc.

Several pharmacological interventions have been tried in the treatment of GD with varying degrees of success. Medications that have shown promise include Bupropion (Han, Hwang \& Renshaw, 2010), Escitalopram (Song et al, 2016), and medications used in the treatment of ADHD such as Atomoxetine and Methylphenidate (Park et al, 2016). While one awaits more conclusive guidance to emerge from RCTs, it might be useful for clinicians to opt for a medication based on the type of co-morbid psychiatric condition (i.e., if there is co-existing depression or anxiety, choose escitalopram or other SSRIs, if ADHD co-exists, choose atomoxetine or methylphenidate, etc.).

For the doctor who comes across a person with GD, be it in adult mental health settings or adolescent settings, as things stand in the UK, a referral to a specialist addiction treatment service might be the best way forward. There are very few exclusive and specialist treatment centres for GD in the UK. 


\section{Conclusion}

Doctors need to be familiar with the presentations and diagnosis of gaming disorder. This will facilitate its early identification and appropriate treatment. With technological advances, it is anticipated that both opportunities and accessibility to gaming will increase, both likely to lead to a rise in gaming-related adverse consequences.

\section{Funding: None}

Acknowledgements: None

\section{References}

American Psychiatric Association. Diagnostic and Statistical Manual of Mental Disorders (DSM-5®) 2013. American Psychiatric Association Publishing: Arlington, VA

Arıcak O T, Dinç M, Yay M, Griffiths MD. Adapting the short form of the Internet Gaming Disorder Scale into Turkish: Validity and reliability. Addicta: The Turkish Journal on Addictions 2019;5, 629-635.

Ballabio M, Griffiths MD, Urbán R, Quartiroli A, Demetrovics Z, Király O. Do gaming motives mediate between psychiatric symptoms and problematic gaming? An empirical survey study. Addict Res Theory 2017;25, 397-408. 
Batchelor J. Games industry generated $\$ 108.4 \mathrm{bn}$ in revenues in 2017 . Retrieved from https://www.gamesindustry.biz/articles/2018-01-31-games-industrygenerated-usd108-4bnin-revenues-in-2017, 2018

Burleigh TL, Griffiths MD, Sumich A, Kuss DJ. A systematic review of the co-occurrence of gaming disorder and other potentially addictive behaviours. Curr Addict Rep 2019; Epub ahead of print. https://doi.org/10.1007/s40429-019-00279-7

Chalk A. Fortnite passes PUBG with 3.4 million concurrent players. Retrieved from https://www. pcgamer.com/fortnite-passes-pubg-with-34-millionconcurrent-players/, 2018

Columb, D, Griffiths, MD, O’Gara, C. Online gaming and gaming disorder: more than just a trivial pursuit. Ir J Psychol Med 2019; 1-9.

de Palo V, Monacis L, Sinatra M, Griffiths MD, Pontes HM, Petro M, Miceli S. Measurement invariance of the nine-item Internet Gaming Disorder Scale across Albania, United States of America, United Kingdom, and Italy. Int J Ment Health AD 2019;17, 935946.

Evren C, Dalbudak E, Topcu M, Kutlu N, Evren B, Pontes HM. Psychometric validation of the Turkish nine-item internet gaming disorder scale-short form (IGDS9-SF). Psych Res 2018;265, 349-354.

Fam JY. Prevalence of internet gaming disorder in adolescents: A meta-analysis across three decades. Scand J Psychol 2018 ;59 (5), pp.524-531.http://doi.org/10.1111/sjop.12459 
Gentile DA, Bailey K, Bavelier D, Funk Brockmeyer J, Young, K. The state of the science about Internet Gaming Disorder as defined by DSM-5: Implications and perspectives, Pediatrics 2017;140, S81-S85.

González-Bueso V, Santamaría J, Fernández D, Merino L, Montero E, Ribas J. Association between internet gaming disorder or pathological video-game use and comorbid psychopathology: a comprehensive review. Int J Env Res Pub He 2018;15, 668.

Griffiths MD, Kuss DJ, King DL. Video game addiction: Past, present and future. Curr Psychiatry Rev 2012;8, 308-318.

Griffiths MD. Problematic technology use during adolescence: Why don't teenagers seek treatment? Educ Health 2015; 33, 6-9.

Griffiths MD. The therapeutic and health benefits of playing videogames. In: Attrill-Smith, A., Fullwood, C. Keep, M. \& Kuss, D.J. (Eds.). The Oxford Handbook of Cyber psychology. (pp. 485-505). Oxford: Oxford University Press, 2019

Han DH, Hwang JW, Renshaw PF. Bupropion sustained release treatment decreases craving for video games and cue-induced brain activity in patients with Internet video game addiction. Exp Clin Psychopharmacol 2010;18, 297-304. 
Hawi NS, Samaha M, Griffiths MD. Internet gaming disorder in Lebanon: Relationships with age, sleep habits, and academic achievement. J Behav Addict 2018;7(1), 70-78.

King DL, Delfabbro PH, Griffiths MD, Gradisar M. Assessing clinical trials of Internet addiction treatment: A systematic review and CONSORT evaluation. Clin Psychol Rev 2011;31, 1110-1116.

King DL, Haagsma MC,Delfabbro PH, Gradisar MS, Griffiths MD. Toward a consensus definition of pathological video-gaming: A systematic review of psychometric assessment tools. Clin Psychol Rev 2013;33, 331-342.

King DL, Delfabbro PH, Wu AM, Doh YY, Kuss DJ, Pallesen S, Sakuma H. Treatment of internet gaming disorder: an international systematic review and CONSORT evaluation. Clin Psychol Rev 2017;54, 123-133.

King DL, Delfabbro PH.Internet Gaming Disorder Theory, Assessment, Treatment, and Prevention, $1^{\text {st }}$ ed., London, United Kingdom; San Diego, CA: Academic Press, an imprint of Elsevier, 2018.

Lemmens JS, Valkenburg PM, Gentile DA. The internet gaming disorder scale. Psychol Assesst 2015;27, 567-582.

Leung H, Pakpour AH, Strong C, Lin Y-C, Tsai M-C, GriffithsMD, Lin C-Y. Measurement invariance across young adults from Hong Kong and Taiwan among three internet-related 
addiction scales: Bergen Social Media Addiction Scale (BSMAS), Smartphone ApplicationBased Addiction Scale (SABAS), and Internet Gaming Disorder Scale-Short Form (IGDSSF9) (Study Part A). Addict Behav 2019;Epub ahead of print. https://doi.org/10.1016/j.addbeh.2019.04.027

Naskar S, Victor R, Nath K, Sengupta C. "One level more:” a narrative review on internet gaming disorder. Ind Psychiatry J 2016;25, 145

Nuyens F, Kuss DJ, Lopez-Fernandez O, Griffiths MD. The experimental analysis of nonproblematic video gaming and cognitive skills: A systematic review. Int J Ment Health AD 2019;17, 389-414.

Park JH, Lee YS, Sohn JH, Han DH. Effectiveness of atomoxetine and methylphenidate for problematic online gaming in adolescents with attention deficit hyperactivity disorder. Hum Psychopharm Clin 2016;31, 427-432.

Pontes H, Griffiths MD. Measuring DSM-5 Internet Gaming Disorder: Development and validation of a short psychometric scale. Comput Hum Behav 2015;45, 137-143.

Pontes HM, Griffiths MD. Portuguese validation of the Internet Gaming Disorder ScaleShort-Form. Cyberpsychol Behav Soc Netw 2016;19(4), 288-293. 
Pontes HM, Macur M, Griffiths MD. Internet gaming disorder among Slovenian primary schoolchildren: Findings from a nationally representative sample of adolescents. $J$ Behav Addict 2016;5(2), 304-310.

Sampogna G, Del Vecchio V, Luciano M, Giallonardo V, Palummo C, Pocai B, Steardo Jr L, Bhugra D, Fiorillo A. Is Internet gaming disorder really a new form of mental disorder? A critical overview. J Psychopathol 2018; 24(3),141-147.

Shi J, Renwick R, Turner NE, Kirsh B. Understanding the lives of problem gamers: the meaning, purpose, and influences of video gaming. Comput. Hum. Behav 2019; 97:291-303.

Song J, Park JH, Han DH, Roh S, Son JH, Choi TY, ... Lee YS (2016). Comparative study of the effects of bupropion and escitalopram on Internet gaming disorder. Psychiat Clin Neuros 70, 527-535.

Stevens MW, King DL, Dorstyn D, Delfabbro PH (2018). Cognitive-behavioral therapy for Internet gaming disorder: a systematic review and meta-analysis. Clin Psychol Psychother 2018;26, 191-203.

Torres-Rodríguez A, Griffiths MD, CarbonellX. The treatment of internet gaming disorder: a briefoverview of the PIPATIC program. Int J Ment Health AD 2018a;16:1000-1015. 
Torres-Rodríguez A, Griffiths MD, Carbonell X, Oberst U. Psychological characteristics of an adolescent clinical sample with Internet Gaming Disorder. J Behav Addict 2018b; 7,707718.

Torres-Rodríguez A., Griffiths MD, Carbonell X,Oberst U. Treatment effectiveness of a specializedpsychotherapy program for Internet Gaming Disorder. J Behav Addict 2018c,7, 939-952.

Torres-Rodríguez A, Griffiths MD, Carbonell X, Farriols-Hernando N, Torres-Jimenez E. Internet gaming disorder treatment: A case study evaluation of four adolescent problematic gamers. Int J Ment Health AD 2019;17, 1-12.

Van Rooij AJ, Kuss DJ, Griffiths MD, Shorter GW, Schoenmakers TM, Van De Mheen D. The (co-) occurrence of problematic video gaming, substance use, and psychosocial problems in adolescents. $J$ Behav Addict 2014;3, 157-165.

World Health Organization. International statistical classification of diseases and related health problems (11th Revision) 2018 - 6C51 Gaming Disorder. Retrieved from https://icd.who.int/browse11/1-m/en\#/http://id.who. int/icd/entity/1448597234

Wu AM, Chen JH, Tong KK, Yu S, Lau JT. Prevalence and associated factors of Internet gaming disorder among community dwelling adults in Macao, China. J Behav Addict 2018;7(1), 62-69. 